\title{
MEMETAKAN KETERAMPILAN PROSES SAINS SISWA SMP KELAS VII DI KABUPATEN GUNUNG KIDUL YOGYAKARTA
}

\author{
Muhammad Izzatul Faqih ${ }^{1}$, Insih Wilujeng ${ }^{2}$ \\ ${ }^{1}$ UIN Walisongo Semarang, ${ }^{2}$ Universitas Negeri Yogyakarta
}

\begin{abstract}
This study aims to map student's science process skills. It was a descriptive research. The data were collected through tests. The data collecting instruments is a multiple choice test. The research conducted at 15 schools in Gunungkidul Regency with three different grade, that is high, medium and low. The schools with the high grade have a highest achievement of science process skills and followed by medium grade and low grade.
\end{abstract}

Keywords: map, science process skills, Gunung Kidul Regency of Yogyakarta

\begin{abstract}
Abstrak
Penelitian ini bertujuan memetakan keterampilan proses sains siswa. Penelitian ini merupakan penelitian deskriptif kuantitatif. Teknik pengambilan data menggunakan tes. Instrumen yang digunakan adalah soal keterampilan proses dalam bentuk pilihan ganda. Penelitian dilakukan pada 15 sekolah di Kabupaten Gunungkidul yang memiliki tiga grade yang berbeda, yaitu: tinggi, sedang, dan rendah. Sekolah dengan grade tinggi memiliki penguasaan keterampilan proses yang paling baik disusul oleh grade sedang dan grade rendah.
\end{abstract}

Kata kunci: pemetaan, keterampilan proses sains, Kabupaten Gunung Kidul Yogyakarta

\section{PENDAHULUAN}

Hakikat sains menurut Sheeba (2013, p.108) "science is simultaneously a body of knowledge and a way of gaining and using that knowledge...." sains secara bersamaan merupakan sebuah tubuh pengetahuan dan sebuah cara untuk mendapatkan dan menggunakan pengetahuan. Sains sebagai body of knowledge merupakan dimensi pengetahuan dari sains (produk), sedangkan sains sebagai a way of investigation merupakan dimensi proses. Produk yang dihasilkan sains berupa pengetahuan. Dimensi pengetahuan dibagi menjadi empat ranah dimana dimensinya meliputi pengetahuan faktual, pengetahuan konseptual, pengetahuan prosedural, dan pengetahuan metakognitif. Pengetahuan tersebut didapatkan melalui serangkaian keterampilan 
proses. Keterampilan proses merupakan bagian yang tidak bisa dipisahkan dari sains.

Karamustafaoğlu (2011, p.26) menyatakan "Science process skills are beneficial in that students can realize by participating in inquiry inthe science laboratory. Science process skills are inseparable in practice from the conceptual understanding that is involved in learning and applying science" keterampilan proses sains berguna karena siswa dapat menyadari dengan berpartisipasi dalam penyelidikan di laboratorium sains. Keterampilan proses sains tidak dapat dipisahkan dalam praktek dari pemahaman konseptual yang terlibat dalam belajar dan menerapkan sains. Oleh karena itu, sesuai dengan Lyndon et al. (2013, p.54) "these skills need to be realized by teachers that it is important in the learning of science" keterampilan ini perlu dipahami oleh guru karena merupakan hal penting dalam pembelajaran sains, selain itu, Jack $(2013$, p.16) "Using science process skills is an important indicator of transfer of knowledge...." Menggunakan keterampilan proses sains merupakan indikator penting dari transfer pengetahuan.

Chiapetta \& Kobala (2010, p.132) membagi keterampilan proses menjadi dua, yaitu keterampilan proses dasar dan terintegrasi. Keterampilan proses dasar meliputi: (1) Observasi, (2) Klasifikasi, (3) Hubungan ruang-waktu, (4) Penggunaan angka, (5) Pengukuran, (6) Prediksi, dan (7) Inferensi, sedangkan keterampilan proses terintegrasi meliputi: (1) Definisi Operasional, (2) Formulasi model, (3) Kontrol variable, (4) Interpretasi data, (5) Hipotesis, dan (6) Eksperimen. Oleh karena itu, untuk mengetahui pemahaman siswa terhadap penguasaan dimensi pengetahuan maka dapat dilakukan dengan mengukur keterampilan proses.

Penilaian dengan teknik dan bentuk tes objektif pilihan ganda untuk mengukur keterampilan proses sains sudah dilakukan oleh banyak peneliti seperti yang dilakukan oleh Tannenbaum (1969, p.1), Dillashaw \& Okay (1980,p.1), Monica (2005, p.v), Halim \& Shahali (2010,p.142), Baharom et al. (2011, p.203), Akyildiz et al. (2012, p.1899). Tes tersebut dapat digunakan untuk mengukur aspek keterampilan proses setiap siswa. Tetapi siswa hanya dapat mengerjakan tes ketika sudah melaksanakan serangkaian keterampilan proses dalam kegiatan praktek dan memahami setiap langkah yang dilakukan.

Pemetaan keterampilan proses sains siswa dengan menggunakan soal tes pilihan ganda belum dilakukan di Kabupaten Gunung Kidul, dimana pemetaan tersebut sangat 
penting dilakukan untuk mengetahui sejauh mana kemampuan siswa dalam menguasai keterampilan proses sains. Dengan mengetahui sejauh mana kemampuan siswa, maka akan dapat dijadikan bahan pertimbanagan dalam menindaklanjuti hasil pembelajaran yang didapatkan.

\section{METODE PENELITIAN}

Jenis Penelitian

Jenis penelitian yang digunakan deskriptif kuantitatif dengan memetakan keterampilan proses sains siswa SMP kelas VII.

Waktu dan Tempat Penelitian

Penelitian ini dilaksanakan di Kabupaten Gunung Kidul Yogyakarta, yaitu di 15 sekolah, antara lain: SMP Negeri 1 Paliyan, SMP Negeri 1 Wonosari, SMP Negeri 2 Playen, SMP Negeri 4 Wonosari, dan SMP Negeri 2 Patuk, SMP Negeri 2 Panggang, SMP Negeri 1 Tanjungsari, SMP Negeri 3 Karangmojo, SMP Negeri 4 Playen, dan SMP Negeri 2 Paliyan, SMP Negeri Botodayaan, SMP Negeri 5 Panggang, SMP Negeri 5 Ngawen, SMP Negeri 3 Ngawen, dan SMP Negeri 3 Saptosari.. Pelaksanaan penelitian dilakukan pada bulan Januari hingga Februari 2015

Subjek Penelitian

Sampel populasi dalam penelitian ini adalah pada kelas VII SMP semester II SMP Negeri 1 Paliyan, SMP Negeri 1 Wonosari, SMP Negeri 2 Playen, SMP Negeri 4 Wonosari, dan SMP Negeri 2 Patuk, SMP Negeri 2 Panggang, SMP Negeri 1 Tanjungsari, SMP Negeri 3 Karangmojo, SMP Negeri 4 Playen, dan SMP Negeri 2 Paliyan, SMP Negeri Botodayaan, SMP Negeri 5 Panggang, SMP Negeri 5 Ngawen, SMP Negeri 3 Ngawen, dan SMP Negeri 3 Saptosari.

Variabel Penelitian

Variabel yang terlibat dalam penelititan ini adalah penguasaan keterampilan proses sains siswa SMP kelas VII.

Prosedur Penelitian

Penelitian dilakukan dengan memberikan tes dengan soal keterampilan proses sains kepada siswa di 15 sekolah. Hasil tes dianalisis secara deskriptif kuantitatif. 
Teknik Analisis Data

Teknik analisis data dilakukan dengan analisis deskriptif kuantitatif. Analisis Hasil Pemetaan dipilah antara masing-masing keterampilan proses sains dasar dan terpadu pada grade tinggi, sedang, dan rendah. Setelah dipilah maka hasilnya dibandingkan satu sama lain.

\section{HASIL DAN PEMBAHASAN}

Pemetaan kemampuan penguasaan keterampilan proses sains dilakukan dengan mengetahui perbandingan keterampilan proses siswa pada berbagai grade sekolah. Pemetaan dilaksanakan pada 15 SMP Negeri dengan tiga status sekolah berbeda. Tiga status sekolah tersebut dibagi berdasarkan peringkat Ujian Nasional (UN) tahun 2013/ 2014, khusus untuk mata pelajaran IPA. Masing-masing status sekolah dipilih 5 sekolah sebagai subjek uji coba. 15 sekolah tersebut adalah sebagai berikut: (1) Grade tinggi: SMP Negeri 1 Paliyan, SMP Negeri 1 Wonosari, SMP Negeri 2 Playen, SMP Negeri 4 Wonosari, dan SMP Negeri 2 Patuk, (2) Grade sedang: SMP Negeri 2 Panggang, SMP Negeri 1 Tanjungsari, SMP Negeri 3 Karangmojo, SMP Negeri 4 Playen, dan SMP Negeri 2 Paliyan, (3) Grade rendah: SMP Negeri Botodayaan, SMP Negeri 5 Panggang, SMP Negeri 5 Ngawen, SMP Negeri 3 Ngawen, dan SMP Negeri 3 Saptosari. Banyaknya siswa sebagai subjek yang digunakan disajikan pada Tabel 1.

Tabel. 1 Subjek Uji Coba Lapangan

\begin{tabular}{llcc}
\hline No & $\begin{array}{c}\text { Nama Sekolah } \\
\text { (SMP N) }\end{array}$ & Kelas & Jumlah \\
\hline 1 & 1 Paliyan & VII & 31 \\
2 & 1 Wonosari & VII & 24 \\
3 & 2 Playen & VII & 31 \\
4 & 4 Wonosari & VII & 26 \\
5 & 2 Patuk & VII & 30 \\
6 & 2 Panggang & VII & 27 \\
7 & 1 Tanjungsari & VII & 24 \\
8 & 3 Karangmojo & VII & 23 \\
9 & 4 Playen & VII & 26 \\
10 & 2 Paliyan & VII & 21 \\
11 & Negeri Botodayaan & VII & 28 \\
12 & 5 Panggang & VII & 25 \\
13 & 5 Ngawen & VII & 27 \\
14 & 3 Ngawen & VII & 26 \\
15 & 3 Saptosari & VII & 18 \\
\hline
\end{tabular}


Sesuai dengan tabel 1, jumlah total responden adalah 387. Jumlah tersebut berkurang dari yang seharusnya dikarenakan ada siswa yang absen. Selain itu, juga terjadi penggantian sekolah pada grade menengah yaitu yang seharusnya SMP N 4 Patuk diganti dengan SMP N 2 Panggang.

Hasil pengujian soal terhadap 387 siswa kemudian digunakan untuk memetakan kemampuan siswa dalam penguasaan keterampilan proses. Keterampilan proses yang diukur terdiri dari keterampilan poses dasar dan terintegrasi. Keterampilan proses dasar meliputi mengobservasi, mengukur, mengelompokkan, dan memprediksi, sedangkan untuk keterampilan proses integrasi meliputi melakukan percobaan (experiment) dan interpretasi. Pemahaman keterampilan proses sains dibagi menjadi tiga kategori, yaitu: tinggi, sedang, dan rendah seperti dapat dilihat pada tabel 2.

Tabel 2. Kategori Pemahaman Keterampilan Proses
\begin{tabular}{ccc} 
No & Kategori & $\begin{array}{l}\text { Persentase } \\
(\%)\end{array}$ \\
\hline 1 & Rendah & $\mathrm{X}>0$ \\
2 & Sedang & $33,3 \%<\mathrm{X} \leq 66,7$ \\
3 & Tinggi & $\mathrm{X}>66,7$ \\
\hline
\end{tabular}

Persentase tersebut didapatkan dengan membagi rerata skor pada keterampilan proses yang dijawab benar oleh siswa dengan jumlah butir soal. Jika dituliskan secara matematis adalah sebagai berikut:

$$
\frac{\overline{\mathrm{x}}}{n} x 100 \% \ldots \ldots
$$

Keterangan:

$\overline{\mathrm{x}}=$ Rerata skor dari keterampilan proses yang dijawab benar oleh siswa $\mathrm{n}=$ jumlah butir soal keterampilan proses

Pada setiap keterampilan proses memiliki jumlah butir soal yang berbeda. Jumlah butir soal keterampilan proses observasi, klasifikasi, prediksi, mengukur, melakukan percobaan dan interpretasi masing-masing secara berturut-turut adalah 5, 7, 5, 6, 7, 6 butir soal.

Hasil pemetaan keterampilan proses masing-masing grade sekolah dapat dilihat pada tabel 3. Informasi yang didapat dilihat pada tabel berupa rerata skor yang diperoleh pada tiap keterampilan proses. Hasil tersebut dipoeroleh dengan menggabungkan data dari lima sekolah untuk tiap grade. 
Tabel 3. Pemetaan Keterampilan Proses Grade Tinggi, Sedang, dan Rendah

\begin{tabular}{llcccccc}
\hline \multirow{2}{*}{ Grade } & & Observasi & Klasifikasi & Prediksi & Mengukur & $\begin{array}{c}\text { Melakukan } \\
\text { Percobaan }\end{array}$ & Interpretasi \\
\hline \multirow{2}{*}{ Tinggi } & Rerata & 2,93 & 5,71 & 3,41 & 4,29 & 4,58 & 4,14 \\
& SD & 1,08 & 1,22 & 1,06 & 1,18 & 1,23 & 1,15 \\
\multirow{2}{*}{ Sedang } & Rerata & 2,78 & 4,91 & 2,84 & 3,73 & 4,10 & 3,63 \\
& SD & 1,03 & 1,42 & 1,14 & 1,34 & 1,53 & 1,21 \\
\multirow{2}{*}{ Rendah } & Rerata & 2,56 & 4,40 & 2,69 & 3,71 & 3,45 & 3,25 \\
& SD & 1,11 & 1,50 & 1,05 & 1,26 & 1,42 & 1,21 \\
\hline
\end{tabular}

Rerata skor pada Tabel 3 kemudian di konversi dengan persamaan 1 menjadi persentase. Hasil konversi dapat dilihat pada tabel 4. Penjelasan secara lebih lengkap tentang tabel 4 dapat dilihat pada Gambar 1. Gambar 1 menunjukkan perbandingan penguasaan keterampilan proses antara tiga grade sekolah yang berbeda sesuai dengan data dalam Tabel 4, masing-masing adalah grade tinggi, sedang, dan rendah.

Tabel 4. Persentase Penguasaan Keterampilan Proses Grade Tinggi, Sedang, dan Rendah

\begin{tabular}{llcccccc}
\hline Grade & & Observasi & Klasifikasi & Prediksi & Mengukur & $\begin{array}{l}\text { Melakukan } \\
\text { Percobaan }\end{array}$ & Interpretasi \\
\hline Tinggi & \multirow{2}{*}{ Persentase } & 58,7 & 81,6 & 68,2 & 71,5 & 65,4 & 69,0 \\
Sedang & $5 \%)$ & 55,6 & 70,2 & 56,8 & 62,1 & 58,6 & 60,5 \\
Rendah & & 51,2 & 62,9 & 53,8 & 61,8 & 49,3 & 54,1 \\
\hline
\end{tabular}

Hasil dari pengolahan data menunjukkan bahwa sekolah yang memiliki grade tinggi memiliki kemampuan pemahaman keterampilan proses yang lebih baik dibandingkan sekolah dengan kategori sedang dan rendah pada semua jenis keterampilan proses. Dilain pihak sekolah dengan kategori rendah memiliki kemampuan pemahaman keterampilan proses yang lebih rendah pada semua jenis keterampilan proses dari grasde sekolah yang lain, sementara kemampuan pemahaman sekolah dengan grade sedang berada diantara grade tinggi dan rendah. Sesuai dengan hasil pemetaan penguasaan keterampilan proses sains yang dilakukan di Kabupaten Gunung Kidul, maka dapat disimpulkan bahwa semakin tinggi grade sekolah maka akan semakin baik penguasaan keterampilan prosesnya.

Rerata persentase skor pemahaman untuk semua keterampilan proses pada grade tinggi adalah paling besar. Persentase skor penguasaan keterampilan proses observasi, 
klasifikasi, prediksi, mengukur, melakukan percobaan, dan interpretasi pada grade tinggi secara berturut-turut adalah 58,7\%, 81,6\%, 68,2\%, 71,5\%, 65,4\%, dan 69,0\%. Persentase tersebut menunjukkan kemampuan observasi dan melakukan percobaan siswa berada pada kategori sedang dan kemampuan klasifikasi, prediksi, mengukur, dan interpretasi berada pada kategori tinggi.

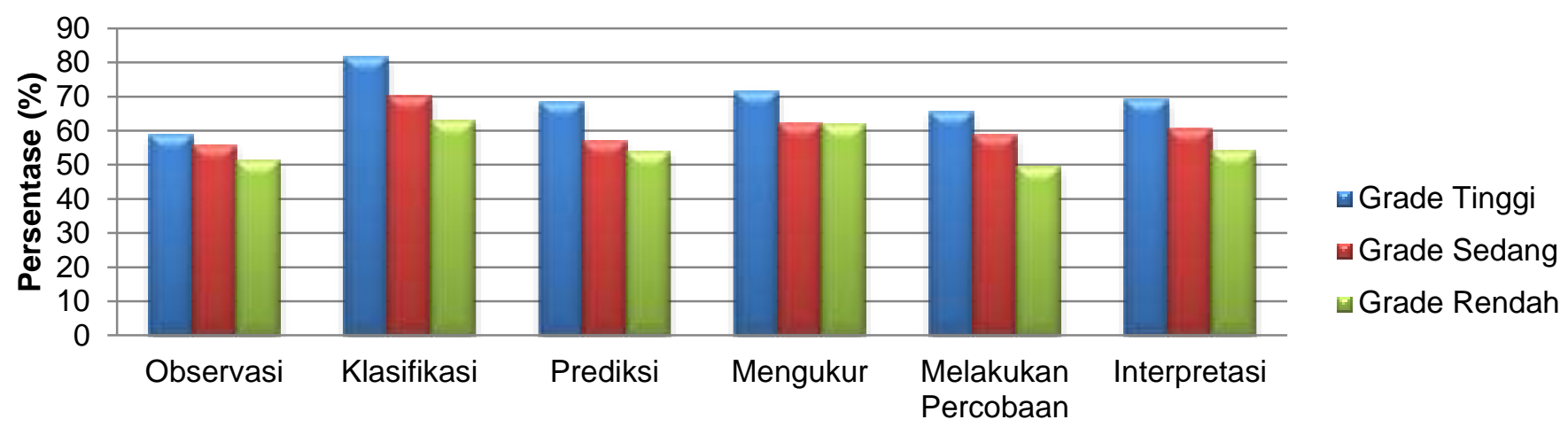

Keterampilan Proses

Gambar 1. Persentase Rerata Skor Keterampilan Proses Grade Tinggi, Sedang, dan Rendah

Selain kemampuan klasifikasi pada sekolah dengan grade sedang $(70,2 \%)$ yang berada dalam kategori tinggi, semua keterampilan pada grade sekolah sedang dan sekolah grade sekolah rendah berada pada kategori sedang. Hal ini menunjukkan bahwa kemampuan pemahaman keterampilan siswa sudah baik.

Jika ditinjau lebih dalam, secara umum semakin rendah grade sekolah maka cenderung memiliki penguasaan keterampilan proses yang semakin rendah pula. Hal tersebut sesuai dengan hasil wawancara yang dilakukan pada guru pada tiap grade yang berhubungan dengan aktivitas praktek di sekolah. Aktivitas praktek yang dilakukan pada grade tinggi memiliki frekuensi yang lebih banyak dibanding grade sedang dan rendah dimana ada sekolah yang melakukan hingga 20 kali dalam satu semester. Dilain pihak sekolah dengan grade sedang dan rendah memiliki frekuensi yang lebih sedikit dan bahkan ada sekolah yang hanya satu atau dua kali melakukan praktek dalam satu semester. Hal ini menunjukkan bahwa sekolah yang sering menerapkan pembelajaran IPA berbasis praktek memiliki penguasaan keterampilan yang lebih baik dibandingkan dengan sekolah yang jarang menerapkan. 


\section{SIMPULAN DAN SARAN}

Hasil dari pemetaan menunjukkan bahwa penguasaan enam keterampilan proses sains yang paling baik berturut-turut adalah grade tinggi, grade sedang dan grade rendah. Perlu adanya peningkatan proses pembelajaran khususnya pada ranah psikomotor siswa kelas VII SMP di Kabupaten Gunung Kidul Yogyakarta.

\section{DAFTAR RUJUKAN}

Akyildiz, M., Altun, E., Demirda, B., Feyzioğlu, B. (2012). Developing a science process skills test for secondary students: validity and reliability study. Educational Consultancy and Research Center, 1899-1906

Baharom, S., Tek, O.E., Tuang, W.Y., Yahaya, A., Yassin, S.M. (2011). The development and validation of an all-encompassing malaysian-based science process skills test for secondary schools. Journal of Science and Mathematics Education in Southeast Asia, 34, 203-236

Chiapetta, E.L., \& Koballa, T.R. (2010). Science Instruction In The Middle and Secondary Schools. Boston: Allyn \& Bacon

Dillashaw, P.G., \& Okay, J.R. (1980). A Test of the Integrated Science Process Skills for Secondary Science Students. National Association for Research in Science Teaching: Boston, USA, 1-14

Halim, L. \& Shahali, E.H.M. (2010). Development and validation of a test of integrated science process skills. Procedia Social and Behavioral Sciences, 9, 142-146

Jack, G.U. (2013). The Influence of Identified Student and School Variables on Students' Science Process Skills Acquisition. Journal of Education and Practice, $4,16-22$

Karamustafaoğlu, S. (2011). Improving the Science Process Skills Ability of Science Student Teachers Using I Diagrams. Eurasian J. Phys. Chem. Educ. 26-38

Lyndon, N., Rauf, R.A.A., Rasul, M. S., Mansor, A.N., \& Othman, Z. (2013). Inculcation of Science Process Skills in a Science Classroom. Asian Social Science: Canadian Center of Science and Education. 47-57

Monica, K.M.M. (2005). Development And Validation Of A Test Of Integrated Science Process Skills For The Further Education And Training Learners. Disertasi doktor, tidak diterbitkan, University Of Petroria, Afrika Selatan.

Sheeba, M. N. (2013). An Anatomy of Science Process Skills in The Light of The Challenges to Realize Science Instruction Leading to Global Excellence in Education. Educationia Confab. 108-123

Tannenbaum, R.S. (1969). The Development of the Test of Science Processes. National 
Association for Research in Science Teaching: Pasadena, California, 1-39.

Thiagarajan, S., Semmel, D.S. \& Semmel, M.I. (1974). Instructional Development For Training Teachers Of Exceptional Children. Leadership Trining Institute/ Special Education: Minneapolis, Minnesota: University Of Minneasota

Uno, H.B. \& Koni, S. (2012). Assessment Pembelajaran. Jakarta: Bumi Aksara. 